Available online at: https://proceeding.researchsynergypress.com/index.php/cpmhs/index

RSF Conference Series: Medical and Health Science

e-ISSN (to be processed) / p-ISSN (to be processed)

Volume 1 Number 1 (2021): 112-119

\title{
Neutrophil Lymphocyte Ratio and C-Reactive Protein in Nondialysis Chronic Kidney Disease
}

\author{
Acang. N ${ }^{1}$, Budiman. $S^{1}$, Sussylawati. $K^{2}$, Vidia. $T^{2}$ \\ ${ }^{1}$ Faculty of Medicine, Universitas Islam Bandung, Indonesia \\ ${ }^{2}$ Cibabat Regional Public Hospital, Cimahi, West Java, Indonesia
}

\begin{abstract}
Background: Chronic kidney disease (CKD) occurs when a disease or condition impairs kidney function, causing kidney damage to worsen over several months. Inflammatory markers such as C-reactive protein (CRP), Interleukine are widely used in CKD. However, those traditional biomarkers have their limitations because of its measurement is costly or inaccessible. Recently, the Neutrophil-to-lymphocyte ratio (NLR) was reported to be associated with inflammation in End-stage renal disease (ESRD). Its measurement is simpler and cheaper4.5. The aim of the present study was to determine whether NLR is associated with CRP in CKD patients.
\end{abstract}

Methods: This cross-sectional and observational analytic study was conducted 12 consecutive Pre Hemodialysis patients ESRD between Mei 2021 and Augustus 2021. Subjects were divided into two groups according to the results of the examination of the CRP and NLR levels. Then analyzed whether there is have a correlation.

Results: The composite endpoint was observed in 12 patients with ESRD; it was found that both of the values of NLR and CRP were equally increased in ESRD patients, although they were not statistically significant.

Conclusion: The present study demonstrated that a high NLR in ESDR and suggesting that NLR may be a useful marker for the prediction of infection in patients with CKD.

Keywords: Chronic renal failure, C-Reactive protein, Neutrophil lymphocyte ratio, End-stage renal disease

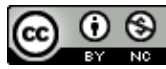

This is an open access article under the CC-BY-NC license

\section{INTRODUCTION}

Chronic kidney disease (CKD) is a condition if the glomerular filtration rate (GFR) $<60$ $\mathrm{ml} /$ minute $/ 1.73 \mathrm{~m} 2$ is found for more than three months 1.7. Chronic kidney disease (CKD) is one of the main problems both in the health and economic fields. Estimates of the global prevalence of CKD worldwide range from $11-13 \%$, with a fairly high mortality rate of around $9 \%$, almost ten to twenty times higher than the general population 2.6. Based on data from the Indonesian Renal Registry (IRR) in 2017, in Indonesia, the number of CKD patients was 30,831, an increase of 6 times compared to 2007.3 The main risk factors for death in CKD patients are infections and cardiovascular disorders. The presence of a chronic inflammatory process can be detected early by examining various inflammatory markers such as C-Reactive Protein and Interleukines in CKD. Even though the traditional inflammatory marker has been widely studied to predict the presence of systemic inflammation, simpler and cheaper markers are still needed. In the last decade, the neutrophil-lymphocyte ratio (RNL) as a new marker of inflammation has been investigated and has been shown to have predictive value in CKD patients9. Cibabat Regional Public Corresponding author Acang. N, Budiman, nuzirwan.acang@unisba.ac.id DOI: (to be processed) 
Hospital (RPH) Cimahi is a type B Education Hospital located in Cimahi City, which accepts patients from Cimahi City and West Java Province. There are about 18 new patients every month. The aim of this study was to find a simple and inexpensive inflammatory mediator for CKD patients to predict the presence of inflammation. The results of this study are expected that clinicians can use RNL be a marker to predict and follow up the occurrence of the inflammatory process in CKD so that it can be monitored and treated early.

\section{LITERATURE REVIEW}

\section{Chronic Kidney Disease ${ }^{1}$}

Definition

The kidney is one of the vital organs that play a role in maintaining the stability of fluids and electrolytes in the body, and its function is to regulate the balance of body fluids, electrolytes, and acid bases by filtration, selective reabsorption of fluids, electrolytes and non-electrolytes, and excrete the excess through urine.1.7 The diagnosis of chronic kidney disease is made if the glomerular filtration rate is less than $60 \mathrm{ml} / \mathrm{min} / 1.73 \mathrm{~m}^{2}$ for more than three months or without kidney damage. 1

\section{Classification}

PGK is divided into five levels/degrees based on the LFG value. Grades 1 to 3 usually have no symptoms or are asymptomatic.

Assign GFR category as follows: 1.10

Table 1. GFR categories in CKD

GFR categories in CKD

\begin{tabular}{|c|c|c|c|}
\hline \\
\hline 1 & & $\geq 90$ & Normal or high \\
\hline & 2 & $60-89$ & Mildly decreased* \\
\hline & $3 a$ & $45-59$ & Mildly to moderately decreased \\
\hline & $3 \mathrm{~b}$ & $30-44$ & Moderately to severely decreased \\
\hline & 4 & $15-29$ & Severely decreased \\
\hline & 5 & $<15$ & Kidney failure \\
\hline
\end{tabular}

Abbreviations: CKD, chronic kidney disease; GFR, glomerular filtration rate.

\section{Epidemiology}

The 2015 Global Burden Disease study also estimated that in 20151.2 million people died from kidney failure, an increase of $32 \%$ since 2005.2.12

Incidence in Indonesia, based on the 2017 Indonesian Renal Registry (IRR) report, the number of new CKD patients was 30,831 people in 2017, a 6-fold increase from 2007.3

\section{Etiology}

The causes of CKD vary globally, and the most common primary diseases causing CKD and ultimately end-stage renal disease (ESRD) are as follow: 1.7

- Diabetes mellitus type 2 (30\% to 50\%)

- Hypertension (27.2\%)

- Primary glomerulonephritis (8.2\%)

- Chronic Tubulointerstitial nephritis (3.6\%) 
- Hereditary or cystic diseases (3.1\%)

- Secondary glomerulonephritis or vasculitis (2.1\%)

- Plasma cell dyscrasias or neoplasm (2.1)

\section{Diagnosis}

The diagnostic approach achieves the expected goals when a directed and chronological examination is carried out, starting from the history, physical examination, diagnosis, and examination supporting routine and special diagnoses.

The history should be directed by collecting all complaints related to retention or accumulation of azotemia toxin, the etiology of CKD, the course of the disease, including all factors that can worsen renal function (GFR). The clinical picture, both subjective and objective complaints, including laboratory abnormalities, has a broad clinical spectrum and involves many organs and depends on the degree of decline in kidney function11. Clinical features of patients with chronic kidney disease include underlying diseases and uremic syndrome Excess urea in the blood will cause symptoms of weakness, lethargy, anorexia, nausea, vomiting, nocturia, fluid overload or volume overload, peripheral neuropathy, pruritus, uremic frost, pericarditis, convulsions to coma and symptoms of complications including hypertension, anemia, osteodystrophy. renal failure, heart failure, metabolic acidosis, and electrolyte balance disorders both sodium, potassium, and chloride.1.7

\section{Laboratory}

The glomerular filtration rate is the best index of renal function and is often assessed by the corrected creatinine or creatinine clearance (CCT) test. The limitations of CCT have inspired researchers to obtain an easy formula for estimating GFR. One method of calculating the LFG formula that has been known for a long time is the Cockcroft -Gault C-G formula). GFR $(\mathrm{ml} / \mathrm{min} /(1.73 \mathrm{~m} 2)=(140$-age $) \mathrm{x}$ Bodyweight $/ 72 \mathrm{x}$ serum creatinine (mg/dl). Blood biochemical abnormalities including decreased hemoglobin levels, increased uric acid levels, hyperkalemia or hypokalemia, hyponatremia, hyperchloremia or hypochloremia, hyperphosphatemia, hypocalcemia, and metabolic acidosis are other supporting data due to complications of urea retention.7

\section{Lymphocyte Neutrophil Ratio}

The ratio of neutrophil-lymphocyte count (RNL) is an inflammatory parameter as a biomarker that is easily accessible and can be calculated simply based on a complete blood count.5 NLR is a simple parameter to easily assess the inflammatory status and has proven useful in stratifying mortality in inflammatory events, as a strong prognostic factor in certain types of cancer at risk of sepsis or as a predictor and marker of inflammatory or infectious pathology and postoperative complications. In immunodeficient patients such as CKD or autoimmune7. Several prospective studies have recently explored the prognostic significance of RNL, particularly in patients with sepsis, and found that RNL measured at ICU admission. These findings remained robust after adjusting for several potential covariates, suggesting that increased RNL was independently associated with unfavorable outcomes in patients with sepsis, CKD, and immunodeficiency7. This ratio is easily integrated into clinical practice and is highly cost-effective. Erick has investigated RNL as an easily measurable parameter to indicate the degree of inflammation and sepsis in $90 \%$ of chronic disease patients.14 Elevated white blood cell and neutrophil components have been shown to be significant predictors of overall and related cardiovascular mortality in CKD patients. In a large group including non-HD CKD patients, increased neutrophil counts 
and decreased lymphocyte counts have been reported to be useful prognostic parameters. Zang (2019) compared CKD-HD patients with healthy subjects. CKD-Non HD patients had higher neutrophil and lower lymphocyte counts5. Several recent studies have evaluated the use of RNL in CKD patients showing a significantly increased RNL in CKD-HD patients compared with healthy subjects. RNL is also considered a quick and simple parameter indicating inflammation and systemic stress. 1

\section{C-reactive protein (CRP)}

C-Reactive Protein (CRP) is a protein that is produced and excreted by liver cells and is produced in large amounts during infection. CRP belongs to the family of pentraxins and, as such, consists of five identical non-covalently linked subunits. The CRP test measures the amount of CRP in the blood to detect inflammation due to an acute condition or to monitor the severity of disease in a chronic condition14. The high sensitivity CRP (hs-CRP) test can detect very small CRP concentrations. Under normal conditions, levels of C-reactive protein in the blood tend to be below. High levels can indicate a serious infection or other medical condition. hs-CRP (high sensitivity CRP).14.15 CRP examination is recommended if the patient has certain complaints that are suspected as signs of infection. Usually, this test is performed on patients with symptoms of a serious bacterial infection. For patients who have been diagnosed with an infection or chronic disease, this test is also carried out to monitor the effectiveness of treatment.

\section{Cibabat Regional Public Hospital Cimahi}

Regional Hospital Cimahi is a type B Education Hospital located in Cimahi City, which accepts patients from the Cimahi city area in particular and generally from the West Java Province. The number of new CKD patients is about 18 new patients each month.

\section{RESEARCH METHODOLOGY}

\section{Research Design}

This study is an observational analytic study with a comparative cross-sectional approach. Where variables were examined before HD

\section{Place and time of research}

The study was conducted in the outpatient and inpatient department of Internal Medicine at Cibabat RPH Cimahi for four months. (Mei-Augustus 2021)

\section{Inclusion criteria}

1. CKD stage $V$ patients aged $18-70$ years who are not yet $\mathrm{HD}$

2. Willing to participate in research.

\section{Exclusion criteria}

1. Sepsis,

2. HIV-AIDS patients

3. Diabetes Mellitus is not controlled

4. Hypertensive Crisis

5. Patients are suffering from solid malignancies and hematological malignancies or aplastic anemia

6. Chronic Liver disease 


\section{FINDINGS AND DISCUSSION}

\section{Baseline data of research subjects}

This study found 12 patients with ESDR Pre-HD. There were woman patients 7 (52.9\%) and fiveman patients (47.1\%) with the mean age of man 54,27 (52,40 $\pm 14,42)$ years and women $55(55 \pm 11,63)$ years. The largest age group is 68 years, and the youngest age is 29 years. The distribution based on age group is as follows: age $30-39$ years old two people (16.7\%), age $40-49$ years old two people $(16.7 \%)$ and age 50-59 years old two people (16.7\%) age 60-69 years old six people (50\%). (Table 1) and (Table 2).

Table 1. Baseline data of a patient ESDR Pre HD (Mei-Augustus 2021)

\begin{tabular}{|c|c|c|c|c|c|c|c|}
\hline \multirow[b]{2}{*}{ No } & \multirow[b]{2}{*}{ Date } & \multirow[b]{2}{*}{ Name } & \multirow[b]{2}{*}{$\mathrm{M} / \mathrm{W}$} & \multirow[b]{2}{*}{$\begin{array}{c}\text { Age } \\
\text { (Years) }\end{array}$} & \multirow[b]{2}{*}{ Address } & \\
\hline & & & & & & CRP & NLR \\
\hline 1 & $8 / 5 / 21$ & Herwani & W & 39 & Cikandang, Ngamprah & $<5.0$ & 4.27 \\
\hline 2 & $19 / 5 / 21$ & Saptilah & $\mathrm{W}$ & 42 & Cipatat & 46.06 & 15 \\
\hline 3 & $25 / 5 / 21$ & Asep Rusmana & $\mathrm{M}$ & 50 & Kebon Rumput Cimahi & 43.63 & 5.27 \\
\hline 4 & $11 / 6 / 21$ & Ade Rodiah & $\mathrm{W}$ & 66 & Rawasari KBB & $<5.0$ & 10.9 \\
\hline 5 & $14 / 6 / 21$ & Uka Sumiati & $\mathrm{W}$ & 61 & Pasirlangu & $<0,5$ & 2.65 \\
\hline 6 & $6 / 7 / 21$ & Ijah Khodijah & $\mathrm{W}$ & 49 & Batujajar KBB & 7.04 & 16.80 \\
\hline 7 & $4 / 8 / 21$ & Sahmi & $\mathrm{M}$ & 63 & Gedung S Kertajaya & 33.99 & 4,11 \\
\hline 8 & $5 / 8 / 21$ & Ade Akhmad R & W & 55 & Jl.Warung Contong & $<5.0$ & 3.29 \\
\hline 9 & $7 / 8 / 21$ & Tati Sugiharti & W & 68 & Jambu Dipa KBB & 10.41 & 6.75 \\
\hline 10 & $10 / 8 / 21$ & Lena Herlina & $\mathrm{W}$ & 60 & Banjaran & 17.34 & 5.7 \\
\hline 11 & $12 / 8.21$ & Jured & $\mathrm{M}$ & 65 & Girimukti & 38.15 & 22.3 \\
\hline 12 & $14 / 8$ & Asep Saefullah & $\mathrm{M}$ & 29 & Kp. Cibanen & 200 & 7.80 \\
\hline
\end{tabular}

Table 2. Distribution of age Respondens

\begin{tabular}{cc}
\hline Age (years) & Frequency $/(\%)$ \\
\hline & \\
$29-39$ & $2 / 16.7$ \\
$40-49$ & $2 / 16.7$ \\
$50-59$ & $2 / 16.7$ \\
$60-69$ & $6 / 50.0$ \\
\hline
\end{tabular}




\section{NLR and CRP level}

The average level of NLR in CKD stage V Pre-HD patients was 11,03 $\pm 10,05$, the lowest value 11.03 $(\mathrm{SD}=10.5)$, the lowest value of 2.65 and the highest value of 22.3. A standard deviation that is higher than the average means that the distribution of data representation is not very good. The average level of CRP in CKD stage V Pre-HD patients was $31.95 \mathrm{pg} / \mathrm{ml}(\mathrm{SD}=55.34)$, the lowest value of $<5.0$ and the highest value of 200. A standard deviation that is higher than the average means that the distribution of data representation is not very good. (Table 3 )

In conclusion, an increase of both INR and CRP were found in ESRD patients, although they were not statistically significant. (Table 3 ) and (Table 4)

Table 3. Respondent's Characteristic

\begin{tabular}{lc}
\hline \multicolumn{1}{c}{ Variable } & Frequency (\%) / Mean \pm SD \\
\hline Sex & \\
- Male & $5(47,1)$ \\
- Female & $7(52,9)$ \\
Age & \\
$-\quad$ Male & \\
- Female & $52,40 \pm 14,42$ \\
NRL & $55 \pm 11,63$ \\
CRP & $11,03 \pm 10,05$ \\
- Not normal & $31,95 \pm 55,34$ \\
NRL Normal & $8(66,7)$ \\
- Not normal & $4(33,3)$ \\
$-\quad$ Normal & $11(91,7)$ \\
\hline
\end{tabular}

Table 4. Correlation between CRP and NRL

\begin{tabular}{lcc}
\hline & R & p-value \\
\hline CRP - NRL & $-0,063$ & 0,845 \\
\hline
\end{tabular}

Conclusion: No significant correlation between CRP and NRL value

\section{Discussion}

A study has been conducted on NLR and CRP in 12 patients with CKD stage V Pre-HD in the inpatient and outpatient departments of Medicine Cibabat GPH Cimahi from Mei 2021 to Augustus 2021. The research samples selected in this study were those that met the inclusion and exclusion criteria. Patients selected in this study were CKD stage V patients with GFR $<15 \mathrm{ml} / \mathrm{m} 2 / 1.73 \mathrm{~m} 2$, aged 18-70 years. A Patient was checked for RNL and CRP levels before the patient underwent HD

\section{Characteristics of the research sample}

The mean age of all patients with CKD stage $V$ in this study was $54.27(\mathrm{SD}=14.42$ ) years. This is almost the same as data Hill (2016) reported that the average age of stage V CKD patients who underwent their first $\mathrm{HD}$ at the age of 55 years. 2

The study of RNL in patients with CKD stage $V$ in Turkey obtained a mean age of $44.73 \pm 10.49$ years. The distribution of the research sample, the male was five people (47.11\%) while women were seven 
people (52,9\%). Harford et al. (2016) stated the prevalence of CKD stage V in men was 59\% and $41 \%$ in women.8

\section{NLR level}

NLR level in the present study increased, mean 31.95 (+/-. Marino (2020) in Italy reported the occurrence of an increase in RNL in CKD patients. 51 Review Okyay (2012) reported, in general, there was an increase in RNL in CKD patients, both CKD-HD and CKD-Non HD and CKD patients with peritoneal dialysis compared to normal subjects

It was found that the LNR level was quite high in patients no four and no 6, namely 10.9 and 16.8 . This situation reflects the examined LNR in CRD.

Yuan (2019) suggests that NLR is associated with the risk of ESRD in Chinese patients with stage 4 CKD. NLR can be used in risk assessment for ESRD among patients with advanced CKD; this application is appealing considering NLR being a routine test.13

\section{CRPLevel}

Oluseyl (2016) concluded, CRP level was increased, mean 31.54 (+/-55.34). The Median CRP value was significantly higher in the CKD group compared to controls $(\mathrm{p}=<0.001)$. Cardiovascular event risk was significantly higher in CKD subjects ( $\mathrm{p}=<0.001$ ). Serum creatinine, BMI, triglyceride, and atherogenic index of plasma correlated positively with CRP.15

Erick M report, CRP appears to be a risk marker for renal function loss. The mechanism of this relationship remains to be clarified. However, the association between CRP, body weight, and relatively elevated creatinine clearance is a hypothesis-generating finding14

In this study, we found a comparable increase in RNL and CRP levels in ESRD patients, although not statistically significant. So it is also recommended LNR examination to predict disease progression and follow-up.

\section{CONCLUSION AND FURTHER RESEARCH}

1. The mean Lymphocyte Neutrophil Ratio in CKD stage V Pre-HD patients was $11.03(+/-10.05)$, where there was a significant increase compared to the normal value.

2. The mean serum C-Reactive protein level in patients with CKD stage $V$ was $31.95(+/-55.34)$ where there is a significant increase compared to the normal value.

3. Both NLR and CRF increased, although they were not statistically significant.

4. NLR suggested a marker of infection in CKD

\section{REFERENCES}

Satyanaayana R.V, Narothama R.A. Chronic Renal Failure. NCBI, July 2021

Hill NR, Fatoba ST, Oke JL, Hirst JA, Callaghan CA, Lessersen DS,et al. Global prevalence of chronic kidney disease- a systematic review and meta-analysis. Plos One.2016; 11(7):1-9

TIM Indonesia Renal Registry. Indonesian renal registry 10th annual report of Indonesian renal registry.Infodatin Kemenkes RI. 2017;1-40.

Forget Patrice, Khalifa Celine, Jena Phelippe, Defour J, Latiene D,Pel MV, et al. What is the normal value of the neutrophil to lymphocyte. 2017. BMC Research Notes.2017; 10(12):1-4 
Zhang, Hai F, Yan L, Wang, Hong Y,Qian Li et al. Neutrophil to lymphocyte Ratio improves the accuracy and sensitivity of pneumonia severity index in predicting 30 day mortality of CAP patients.Clin Lab Jornal.2019;65(10):

Collins A, Foley R Chavers B, Gilberton B,Herzog C,Shani A,et al.U.S. Renal Data System, USRDS 2010 Annual Data Report 2010;1:1-16 